\title{
Increase in CSF protein in association with ECT
}

\author{
G. S. A L E X O P O U L OS, J . H. K OCS I S, A N D P. E. S T OKES
}

From the Department of Psychiatry, Division of Psychobiology, Payne Whitney Clinic, New York Hospital-Cornell University Medical Center, New York, USA

SUMMARY In this case report we describe a 44 year old man who developed a transient increase of CSF protein in association with a course of electroconvulsive therapy for depression. Neurological evaluation failed to show any other abnormalities. The finding seems to reflect a transient dysfunction of the blood-brain barrier.

Electroconvulsive therapy (ECT) is thought not to increase CSF protein (Essman, 1973). Neither patients who underwent a course of ECT (Jacobs, 1944; Eiduson et al., 1960) nor experimental animals (Spiegel-Adolf et al., 1945) which received repeated electroshocks over a shorter time showed increases in CSF protein. To our knowledge there is only one reported case of a patient who developed a moderate temporary elevation of CSF protein after a single ECT. However, this patient was diabetic, hypertensive, and arteriosclerotic, and this made the changes in the CSF difficult to interpret (Jacobs, 1944).

In this report we describe a physically healthy, depressed patient who developed an increase in CSF protein after a course of ECT. The CSF protein returned to its previous values shortly after ECT was discontinued.

\section{Case report}

A 44 year old white man (WH) was admitted to the Psychobiology Study Unit of the Payne Whitney Clinic in 1977 for severely depressed mood, suicidal ideation, guilt preoccupations, and severe vegetative signs. He had a history of two previous episodes of psychotic depression at ages 27 and 43 years, which responded to hospital treatment. $\mathrm{He}$ had been asymptomatic and steadily employed during the intervals. Within several days of admission he developed affective delusions and hallucinations, stopped eating and drinking, and required tube feeding. His medical history, physical and neurological examination, and routine laboratory tests including EEG were unremarkable. After 14

Address for reprint requests: Dr George S. Alexopoulos, Payne Whitney Clinic, New York Hospital, Cornell University Medical Center, Room P-277, 525 East 68 Street, New York, NY 10021, USA.

Accepted 12 June 1978 days without drugs, he had a 27 day trial of amitriptyline $250 \mathrm{mg}$ daily. Because of poor antidepressant response the drug was discontinued, and a course of 11 ECT sessions was administered at a frequency of three treatments per week with good antidepressant response. However, he relapsed within a week and was given one ECT weekly for three consecutive weeks. He was discharged without symptoms and advised to return to work and to have maintenance ECT bimonthly as an outpatient. Three months after discharge he remained asymptomatic, had no physical complaints, and reported that he functioned well at work. As part of a continuing study of depression the patient had undergone lumbar punctures during the drugfree period and during amitriptyline treatment. On both occasions the CSF was clear with no cells and normal glucose values. Protein values were 0.42 and $0.64 \mathrm{~g} / 1$ respectively, measured by turbidimetry (Tietz, 1976). A third lumbar puncture, performed three days after the eleventh ECT, revealed a CSF protein of $0.94 \mathrm{~g} / 1$, while the rest of the CSF values remained normal. A repeat cytological examination, CSF immunoelectrophoresis, sedimentation rate, cryptococcal antigen, skull and spine radiographs, EEG, ${ }^{99} \mathrm{Tc}$ brain scan, and CAT scans with and without contrast enhancement were normal. Another lumbar puncture performed 13 days after the last ECT showed a decrease of CSF protein to $0.6 \mathrm{~g} / 1$, with no cells and normal glucose.

\section{Comment}

It is important for the neuropsychiatrist to be aware of the possibility that ECT may increase the CSF protein. While this finding warrants careful neurological evaluation, this knowledge may prevent unreasonable and expensive investigations, 
as well as undue worry for the patient and the clinician. This case received neurological consultation and extensive investigation to rule out causes of increase in CSF protein.

A mild increase in CSF protein was observed during the treatment with amitriptyline. Although the value was above normal limits $(0.15-0.45 \mathrm{~g} / \mathrm{l})$ it was close to the value of the drug-free period which was in the upper normal levels. Tricyclic antidepressants are not thought to increase CSF protein. In a series of 13 inpatients who received tricyclic drugs in our centre, we observed no difference in CSF protein before and after treatment.

Increase in CSF protein reflects a dysfunction of the blood-brain barrier. Total CSF protein, however, is not a sensitive index of such a dysfunction. Fractions of CSF proteins of different molecular size are more sensitive markers of disturbance of the blood-brain barrier (Schliep and Felgenhauer, 1974). Siemes et al. (1978) showed that children with febrile convulsions had an increase of CSF albumin which had a linear correlation with the duration of convulsions. However, no significant increase in total CSF protein was found. In animal experiments the dysfunction of blood-brain barrier after seizures was measured by injecting radioisotope labelled albumin which does not cross the blood-brain barrier. Its appearance in the brain was studied by means of autoradiography. It was shown that after electroshock the permeability of the blood-brain barrier increased, especially in the grey matter, and was particularly pronounced in the thalamic and hypothalamic areas (Lee and Olszewski, 1961; Lorenzo et al., 1972; Rozdilsky and Olszewski, 1957. Both the work on epileptic seizures and on those electrically induced indicate that seizures can cause a dysfunction of the blood-brain barrier with a consequent increase of at least certain fractions of CSF proteins. This kind of disturbance may have occurred in our case to such a degree that even a crude index like total CSF protein was affected. The clinical significance of the temporary dysfunction of the blood-brain barrier remains unknown.

\section{References}

Eiduson, S., Brill, N. Q., and Crumpton, E. (1960). The effect of electro-convulsive therapy on spinal fluid constituents. Journal of Mental Science, 106, 692-698.

Essman, W. B. (1973). Neurochemistry of Cerebral Electroshock, pp. 17-21. Spectrum Publications: New York.

Jacobs, J. S. L. (1944). The effect of electric shock therapy upon cerebrospinal fluid pressure, protein and cells. American Journal of Psychiatry, 101, 110 112.

Lee, J. C., and Olszewski, J. (1961). Increased cerebrovascular permeability after repeated electroshocks. Neurology (Minneapolis), 11, 515-519.

Lorenzo, A. V., Shirahige, I., Liang, M., and Barlow, C. F. (1972). Temporary alteration of cerebrospinal permeability to plasma protein during drug-induced seizures. American Journal of Physiology, 223, 268-on 277.

Rozdilsky, B., and Olszewski, J. (1957). Permeability of cerebral blood vessels studied by radioactive iodinated bovine albumin. Neurology (Minneapolis), 7, 270-279.

Schliep, G., and Felgenhauer, K. (1974). The $\alpha_{2}$. macroglobulin level in cerebrospinal fluid: A para- 0 meter for the condition of the blood-CSF barrier. Journal of Neurology, 207, 171-181.

Siemes, H., Siegert, M., and Hanefeld, F. (1978). Febrile convulsions and blood-cerebrospinal fluid barrier. Epilepsia, 19, 57-66.

Spiegel-Adolf, M., Spiegel, E. A., Ashkenaz, E. W., and Lee, A. J. (1945). Physiochemical effects of electrically induced convulsions. Journal of Neuropathology and Experimental Neurology, 4, 277-290.

Tietz, N. W. (1976). Fundamentals of Clinical Chemistry, p. 371. W. B. Saunders: Philadelphia. 